\title{
Canopy Multilayering and Woody Species Diversity of a Subtropical Evergreen Broadleaf Forest, Okinawa Island ${ }^{1}$
}

\author{
Akio Hagihara, ${ }^{2,3}$ S. M. Feroz, ${ }^{2}$ and Masatsugu Yokota ${ }^{2}$
}

\begin{abstract}
Woody species diversity and the spatial distribution of trees in a subtropical evergreen broadleaf forest on a silicate substrate, Okinawa Island, were investigated to determine the forest's architectural stratification. The forest stand consisted of four architectural layers. The values of Shannon's index $H^{\prime}$ and Pielou's index $\mathcal{F}^{\prime}$ tended to increase from the top layer downward, except for the bottom layer. The lower layers contained many species relative to their smaller height ranges. High woody species diversity of the forest depended on small trees. This trend of species diversity was different from that of forest on a limestone substrate on Okinawa Island, where high woody species diversity depended on large trees. Conservation of small trees in the lower layers, especially the bottom layer, is indispensable to maintain diversity in Okinawan evergreen broadleaf forests. Castanopsis sieboldii (Mak.) Hatusima had the highest importance value in all layers, indicating that it is typically a facultative shade species as well as a climax species. The spatial distribution patterns of trees were found to be random in the lower three layers, but in the top layer clumping seemed to occur at three spatial scales. A high degree of overlapping in spatial distributions of trees among the layers suggested that light cannot penetrate easily into the lower layers. As a result, most species in the lower layers must be shade-tolerant. Mean weight index decreased from the top toward the bottom layer, and tree density increased from the top downward. This trend resembled the mean weight-density trajectory of self-thinning plant populations.
\end{abstract}

The EAST AND southeast coastal zone of the Asian continent lacks the subtropical dry belt, which elsewhere in the world separates temperate forest areas from the humid tropics. The subtropical zone, which includes a chain of islands from Okinawa to Taiwan, is sufficiently moist to allow the development of subtropical forests. Thus forest climates with

${ }^{1}$ This study was financed in part by a Grant-in-Aid for Scientific Research (No. 16201009) from the Ministry of Education, Culture, Sports, Science, and Technology, and by the 21st Century Center of Excellence (COE) Program of the University of the Ryukyus. Manuscript accepted 21 September 2007.

${ }^{2}$ Laboratory of Ecology and Systematics, Faculty of Science, University of the Ryukyus, Okinawa 903-0213, Japan.

${ }_{3}^{3}$ Corresponding author: (e-mail: amyh@sci.u-ryukyu .ac.jp).

Pacific Science (2008), vol. 62, no. 3:363-376

(C) 2008 by University of Hawai'i Press

All rights reserved sufficient rainfall exist in coastal areas of the western Pacific from subarctic eastern Siberia to equatorial Southeast Asia, giving rise to a sequence of five forest formations, including subarctic evergreen conifer forests, cool-temperate deciduous broadleaf forests, warm-temperate lucidophyll forests, subtropical forests, and tropical rain forests (Kira 1991). Therefore, the subtropical forest in the Okinawa Islands is precious from a phytogeographical standpoint.

In the northern part of Okinawa Island, there exists the subtropical evergreen broadleaf forest, which is characterized by higher woody species diversity than forests in mainland Japan (Itô 1997). Measures of species diversity play a central role in ecology and conservation biology. The most commonly employed measures of species diversity are species richness (number of species) and evenness (similarity in abundance among species, sometimes known as equitability). High evenness is conventionally equated with high diversity (Pielou 1975, Magurran 1988). In 
addition, the spatial distribution of trees has been a major source of interest for plant ecologists because of its potential role in explaining the coexistence of tree species in speciesrich forests (Bunyavejchewin et al. 2003).

It is known that woody species diversity increases sharply along a latitudinal thermal gradient from higher latitudes to the tropics (Kira 1991, Ohsawa 1995) in accordance with a greater degree of stand multilayering toward warmer regions (Hozumi 1975, Yamakura 1987, Kimmins 2004). The canopy multilayering structure (i.e., architectural stratification) is an important factor in maintaining higher woody species diversity (Roberts and Gilliam 1995, Lindgren and Sullivan 2001, Feroz et al. 2006a).

However, the effect of architectural stratification on the woody species diversity of subtropical evergreen broadleaf forests of Okinawa Island has been little studied. Therefore, the objectives of our study were to quantify woody species diversity and spatial distributions of trees on the basis of their architectural stratification.

\section{MATERIALS AND METHODS}

\section{Study Site and Sampling}

The study was conducted in the Subtropical Field Science Center at Yona, University of the Ryukyus, located in the northern part of Okinawa Island $\left(26^{\circ} 45^{\prime} \mathrm{N}, 128^{\circ} 10^{\prime} \mathrm{E}\right)$. The bedrock is mainly silicate, and the soil $\mathrm{pH}$ is 4.35 (Alhamd et al. 2004, Alhamd and Hagihara 2004, Feroz et al. 2006a).

A sampling plot area of $750 \mathrm{~m}^{2}$ (25 by 30 $\mathrm{m})$ was established as a representative of the subtropical evergreen broadleaf forest in the northern part of Okinawa Island and divided into 120 quadrats $(2.5$ by $2.5 \mathrm{~m})$. The slope, altitude, and direction of the plot were 24.5 degrees, $250 \mathrm{~m}$ above sea level, and northwest west, respectively.

\section{Climate}

Figure 1 is a Walter-type climatic diagram, which shows seasonal changes in mean monthly temperature and rainfall (19952004, Meteorological Station in Nago City). The mean monthly minimum temperature and the mean monthly maximum temperature are, respectively, $16.4 \pm 0.3(\mathrm{SE}){ }^{\circ} \mathrm{C}$ in January and $28.8 \pm 0.2(\mathrm{SE})^{\circ} \mathrm{C}$ in July. The mean annual temperature is $22.8 \pm 0.3$ (SE) ${ }^{\circ} \mathrm{C}$. The warmth index is $213.5 \pm 1.3$ (SE) ${ }^{\circ} \mathrm{C}$ month, which is within the range of 180 to $240^{\circ} \mathrm{C}$ month of the subtropical region defined by Kira (1977). The mean monthly rainfall is over $100 \mathrm{~mm}$ throughout the year except for $94 \pm 17 \mathrm{~mm}$ in January. The mean annual rainfall is $2,401 \pm 136(\mathrm{SE}) \mathrm{mm}$. Typhoons frequently occur between July and October, bringing high rainfall and strong winds.

\section{Field Measurement}

All woody plants above $0.10 \mathrm{~m}$ were numbered and identified by species according to the nomenclature by Hatusima (1990). The measurements obtained for the area were tree height $(H)$, diameter at breast height (DBH), and stem diameter at a height of $1 / 10$ of tree height $\left(D_{0.1 \mathrm{H}}\right)$.

\section{Architectural Stratification}

To identify the multilayering structure of the forest stand, the $M-w$ diagram (Hozumi 1975) was used. Tree weight $w$ was assumed to be proportional to $D_{0.1 \mathrm{H}}{ }^{2} \mathrm{H}$ (because the $w$ is not the unit of mass, $w$ is termed weight index), and it was arranged in descending order. Average weight index $M_{n}$ from the maximum weight index $w_{1}$ to the $n$th weight index was calculated using the form of $M_{n}=\sum_{i=1}^{n} w_{i} / n$ ( $n=1, \ldots$, total number of trees). If the $M$ $w$ diagram was constructed by plotting the values of $M$ against the corresponding values of $w$ on logarithmic coordinates, then some segments on the $M-w$ diagram could be formed. Each segment is related to the layer with the specific characteristics of the betatype distribution functions designated by Hozumi (1971, 1975). Hozumi (1975) pointed out that the segments on the $M-w$ diagram can be written by either of the following equations:

$$
\begin{gathered}
M=A w+B \\
M=C w^{b}
\end{gathered}
$$




\section{Annual mean temperature : $22.7^{\circ} \mathrm{C} \quad$ Annual rainfall : $2401 \mathrm{~mm} \mathrm{yr}^{-1}$}

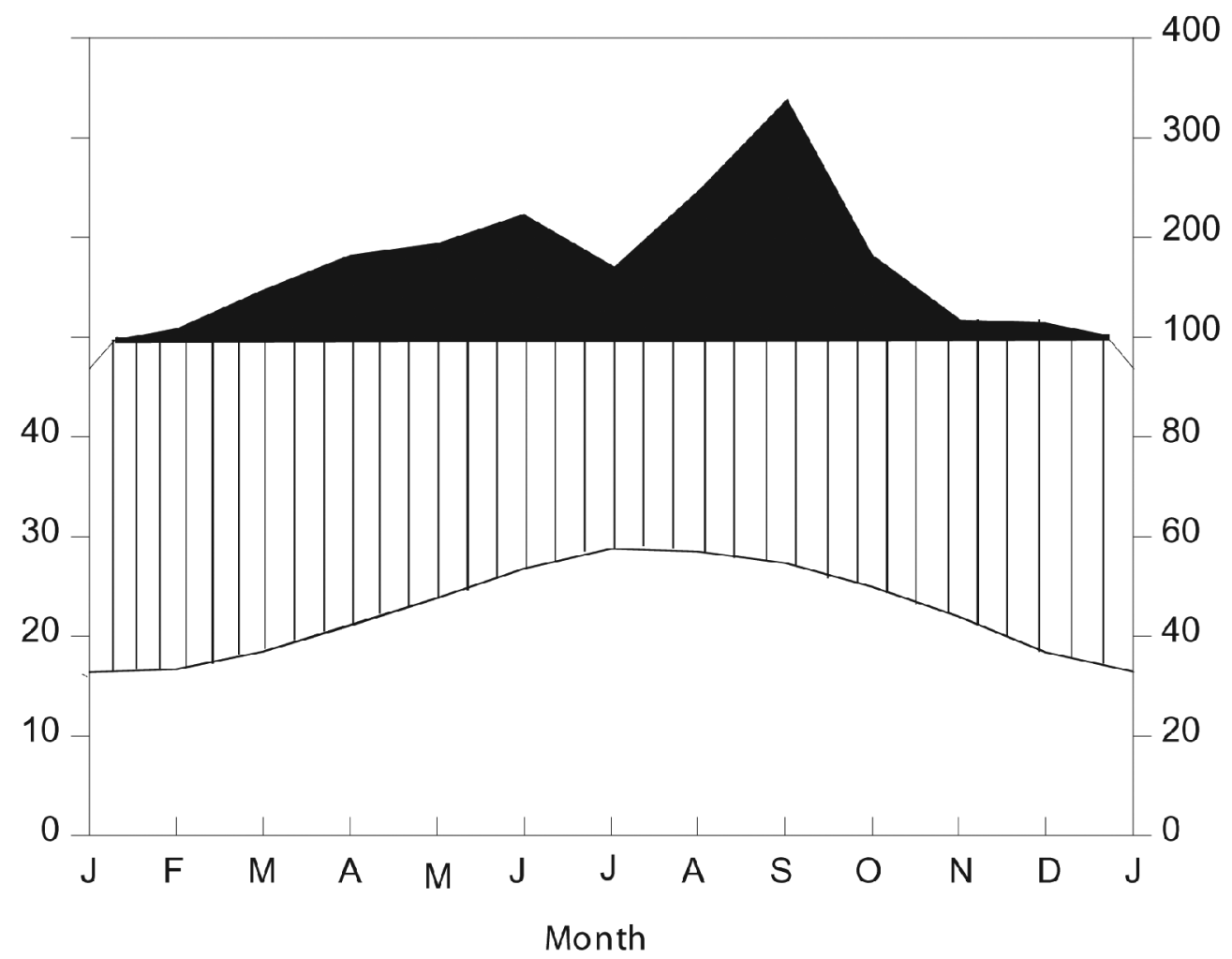

Figure 1. Walter-type climatic diagram (average during $10 \mathrm{yr}$ : 1995-2004) based on the data obtained from the meteorological station located $35 \mathrm{~km}$ south of the study site.

where $A, B, C$, and $b$ are coefficients. These functions reflect some aspect of the manner of packing trees into the three-dimensional space of a forest stand. Hozumi (1975) found that the number of layers distinguished by the $M-w$ diagram increases along a latitudinal thermal gradient from one in the northern conifer forest to four in the tropical rain forest.

\section{Species Diversity}

Shannon's index (MacArthur and MacArthur 1961) $H^{\prime}$ and Pielou's (1969) index $\mathcal{F}^{\prime}$ were used to measure woody species diversity or equitability (evenness):

$$
\begin{gathered}
H^{\prime}=\sum_{i=1}^{s} \frac{n_{i}}{N} \log _{2} \frac{N}{n_{i}} \\
\mathcal{f}^{\prime}=\frac{H^{\prime}}{H_{\max }^{\prime}} \quad\left(H_{\max }^{\prime}=\log _{2} S\right)
\end{gathered}
$$

where $n_{i}$ is the number of individuals of the $i$ th species, $N$ is the total number of individuals, and $S$ is the total number of species, and the unit of $H^{\prime}$ is the bit, or the unit of entropy (e.g., Goldman 2005).

\section{Species Dominance}

Dominance of a species was defined by the importance value $I V \%$ of the species. 


$$
\begin{aligned}
I V= & \left(\frac{n_{i}}{\sum_{i=1}^{Q} n_{i}} \times 100+\frac{a_{i}}{\sum_{i=1}^{Q} a_{i}} \times 100\right. \\
& \left.+\frac{f_{i}}{\sum_{i=1}^{Q} f_{i}} \times 100\right) / 3
\end{aligned}
$$

where $a_{i}$ is the basal area at a height of $H / 10$ of the $i$ th species, $f_{i}$ is the number of quadrats in which the $i$ th species appeared, and $Q$ is the total number of quadrats.

\section{Spatial Distributions of Trees}

The unit-size $m_{u}^{*}-m_{u}$ method with successively changing quadrat size (Iwao 1972) was used to analyze the spatial distribution patterns of trees. Mean density $m_{u}$ is defined as:

$$
m_{u}=\frac{\sum_{j=1}^{q_{u}} n_{j}}{q_{u}}
$$

where $n_{j}$ is the number of individuals in the $j$ th quadrat, and $q_{u}$ is the total number of quadrats when the quadrat size is $u$. The $q_{u}$ values were $120,60,30,15,7,4$, and 2 , respectively, for the $u$-values of $1,2,4,8,16$, 30 , and 60 . Mean crowding $m_{u}^{*}$ is defined by Lloyd (1967) as:

$$
m_{u}^{*}=\frac{\sum_{j=1}^{q_{u}} n_{j}\left(n_{j}-1\right)}{\sum_{j=1}^{q_{u}} n_{j}}
$$

For any quadrat size, trees are considered to be randomly distributed when $m_{u}^{*}=m_{u}$, aggregated when $m_{u}^{*}>m_{u}$, and uniformly distributed when $m_{u}^{*}<m_{u}$. To provide knowledge on the distribution pattern of clumps, Iwao (1972) proposed the $\rho$-index.

$$
\rho_{u}=\frac{m_{u}^{*}-m_{u-1}^{*}}{m_{u}-m_{u-1}}
$$

where for the smallest quadrat size $(u=1)$, $\rho_{1}=m_{1}^{*} / m_{1}$. This index indicates the ratio of the increment of $m_{u}^{*}$ against $m_{u}$ while the quadrat size increases from the $(u-1)$ th to the $u$ th, and it takes a constant value as far as the $m_{u}^{*}$-on- $m_{u}$ regression remains linear. When the values of $\rho_{u}$ are plotted against the quadrat sizes, a peak suggests that the clump area lies somewhere between the two corresponding quadrat sizes.

\section{Overlapping in Spatial Distributions of Trees}

On the basis of the concept of mean crowding proposed by Lloyd (1967), Iwao (1977) derived the $\omega$-index for analyzing spatial association between species. The $\omega$-index was applied to measure the degree of overlapping in spatial distributions of trees among layers, with successive changes of quadrat size $u$. The numbers of quadrats were $120,60,30$, 15 , and 7 , respectively, for the $u$-values of 1 , $2,4,8$, and 16 .

$$
\begin{gathered}
\omega_{(+)}=\frac{\sqrt{m_{\mathrm{AB}}^{*} m_{\mathrm{BA}}^{*}}-\sqrt{m_{\mathrm{A}} m_{\mathrm{B}}}}{\sqrt{\left(m_{\mathrm{A}}^{*}+1\right)\left(m_{\mathrm{B}}^{*}+1\right)}-\sqrt{m_{\mathrm{A}} m_{\mathrm{B}}}} \\
\text { for } m_{\mathrm{AB}}^{*} m_{\mathrm{BA}}^{*} \geq m_{\mathrm{A}} m_{\mathrm{B}} \\
\omega_{(-)}=\sqrt{\frac{m_{\mathrm{AB}}^{*} m_{\mathrm{BA}}^{*}}{m_{\mathrm{A}} m_{\mathrm{B}}}}-1 \\
\text { for } m_{\mathrm{AB}}^{*} m_{\mathrm{BA}}^{*} \leq m_{\mathrm{A}} m_{\mathrm{B}}
\end{gathered}
$$

In equation (9), $m_{\mathrm{AB}}^{*}$, mean crowding on layer A by layer $\mathrm{B}$, is defined as:

$$
m_{\mathrm{AB}}^{*}=\frac{\sum_{j=1}^{Q} n_{\mathrm{A} j} n_{\mathrm{B} j}}{\sum_{j=1}^{Q} n_{\mathrm{A} j}}
$$

where $Q$ is the total number of quadrats, and $n_{\mathrm{A} j}$ and $n_{\mathrm{B} j}$ are the number of individuals belonging to the $j$ th quadrat in layer A and layer $\mathrm{B}$, respectively. Similarly, $m_{\mathrm{BA}}^{*}$, mean crowding on layer B by layer A, is defined as:

$$
m_{\mathrm{BA}}^{*}=\frac{\sum_{j=1}^{Q} n_{\mathrm{A} j} n_{\mathrm{B} j}}{\sum_{j=1}^{Q} n_{\mathrm{B} j}}
$$

The interlayer mean crowding indicates the mean number of individuals of the other layer per individual of the subject layer per quadrat.

On the other hand, $m_{\mathrm{A}}^{*}$, mean crowding within layer $\mathrm{A}$, is defined as:

$$
m_{\mathrm{A}}^{*}=\frac{\sum_{j=1}^{Q} n_{\mathrm{A} j}\left(n_{\mathrm{A} j}-1\right)}{\sum_{j=1}^{Q} n_{\mathrm{A} j}}
$$

Similarly, $m_{\mathrm{B}}^{*}$, mean crowding within layer B, is defined as:

$$
m_{\mathrm{B}}^{*}=\frac{\sum_{j=1}^{Q} n_{\mathrm{B} j}\left(n_{\mathrm{B} j}-1\right)}{\sum_{j=1}^{Q} n_{\mathrm{B} j}}
$$


The intralayer mean crowding indicates the mean number of the other individuals per individual of the subject layer per quadrat. The symbol $m_{\mathrm{A}}\left(=\sum_{j=1}^{Q} n_{\mathrm{Aj} j} / Q\right)$ and $m_{\mathrm{B}}\left(=\sum_{j=1}^{Q} n_{\mathrm{B} j} / Q\right)$ stand for the mean density per quadrat in layer A and layer B, respectively. The value of $\omega$ changes from the maximum of +1.0 for complete overlapping, through 0.0 for independent occurrence, to the minimum of -1.0 for complete exclusion.

\section{RESULTS}

\section{Architectural Stratification}

The $M-w$ diagram is illustrated in Figure 2. In the current forest, there were four architectural layers, which were confirmed using the first and the second derivatives on the $M-w$ diagram (Feroz et al. 2006a). Weight indices at boundaries between the layers were estimated as $508,3.18$, and $0.00953 \mathrm{~cm}^{2} \mathrm{~m}$.

Figure 3 shows the relationship between tree height $H$ and weight index $w$ (cf. Kira and Ogawa 1971), which was formulated as follows:

$$
\frac{1}{H}=\frac{1}{1.37 w^{0.361}}+\frac{1}{21.0}
$$

The heights of the boundaries were determined as 8.0, 1.9, and $0.25 \mathrm{~m}$ by substituting the weight indices at boundaries obtained earlier for $w$ in equation (10). Therefore, the height range was $8.0 \mathrm{~m}<H \leq 16.5 \mathrm{~m}$ for the top layer, $1.9 \mathrm{~m}<H \leq 8.0 \mathrm{~m}$ for the second layer, $0.25 \mathrm{~m}<H \leq 1.9 \mathrm{~m}$ for the third layer, and $0.10 \mathrm{~m} \leq H \leq 0.25 \mathrm{~m}$ for the bottom layer (Table 1). The height range showed a geometric progression with an equal ratio of 2: i.e., approximately $2^{1}(\cong 16.5 / 8.0), 2^{2}$ $(\cong 8.0 / 1.9)$, and $2^{3}(\cong 1.9 / 0.25)$ in the top, second, and third layers, respectively.

\section{Woody Species Diversity in the Stratified Forest Stand}

The values of $H^{\prime}$ and $\mathcal{f}^{\prime}$ were, respectively, $2.75 \mathrm{bit}$ and 0.66 for the top layer, $4.37 \mathrm{bit}$ and 0.81 for the second layer, $4.73 \mathrm{bit}$ and 0.80 for the third layer, 4.33 bit and 0.73 for the bottom layer, and 4.83 bit and 0.82 for the total stand (Table 1). These results indicate that the values of the diversity indices $H^{\prime}$ and $f^{\prime}$ tended to increase from the top layer downward, except for the bottom layer.

In addition, the highest diversity was in the third layer. This is because the highest species richness (56 species) and evenness in the third layer resulted in the highest $H^{\prime}$-value. On the other hand, the lowest diversity was in the top layer. This is because the lowest species richness (18 species) and evenness resulted in the lowest $H^{\prime}$-value. The values of $H^{\prime}$ in the second layer and in the bottom layer were nearly the same, and $\mathcal{f}^{\prime}$ was higher in the second layer than in the bottom layer. This is because an increase of species richness from the second layer (42 species) to the bottom layer (51 species) could compensate for a decrease of evenness $\mathcal{f}^{\prime}$ from the second layer to the bottom layer.

\section{Species Dominance}

Table 2 lists importance values (IV) of 10 woody species in order of species rank in the $750 \mathrm{~m}^{2}$ sampling plot, together with the four layers. A total of 26 families, 43 genera, 60 species, and 4,684 individuals was recorded. The most species-rich family was Rubiaceae, which had 12 species. Symplocos, Lasianthus, and Ilex were the species-rich genera, each of which had five species. Of the 60 species, only three species $(5 \%)$ consisted of a single individual. Castanopsis sieboldii (Mak.) Hatusima appeared in all layers with the highest importance value, especially with a tremendously high value of $44 \%$ in the top layer. This species had the largest population size, with a large number of trees, saplings, and seedlings (data not shown). These phenomena indicate that $C$. sieboldii is the dominant and climax species in the forest. Schima wallichii (DC.) Korth. was the second dominant species in terms of importance value $(9.30 \%)$ in the total stand. The high importance value $(22.8 \%)$ of $S$. wallichii in the top layer and the very low importance value (ranging from 0.62 to $1.69 \%$ ) in the lower three layers indicate the heliophilic nature of the species. Some of the high-rank species, such as Myrsine seguinii Lév., Ardisia quinquegona Bl., Smilax 


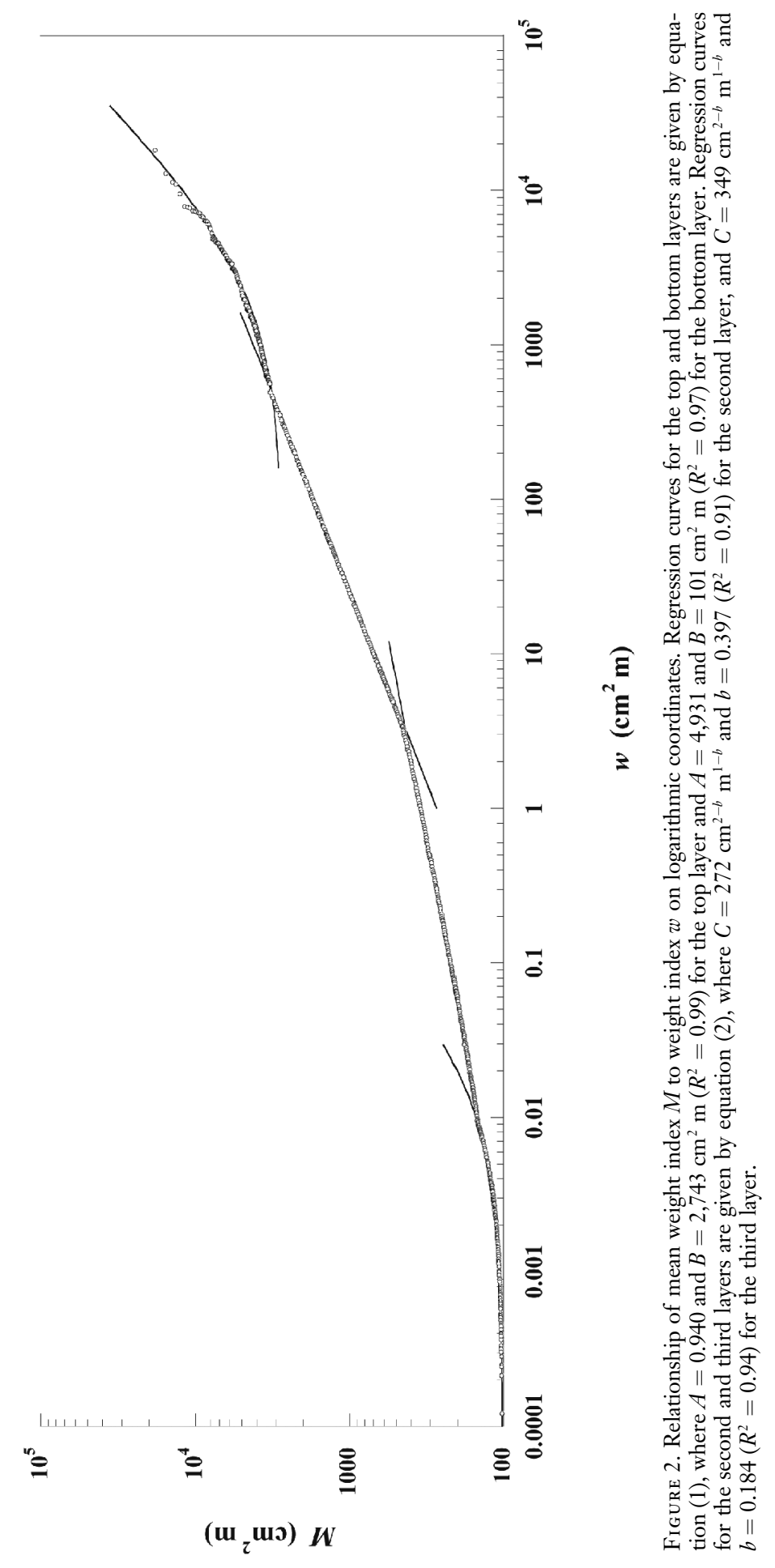




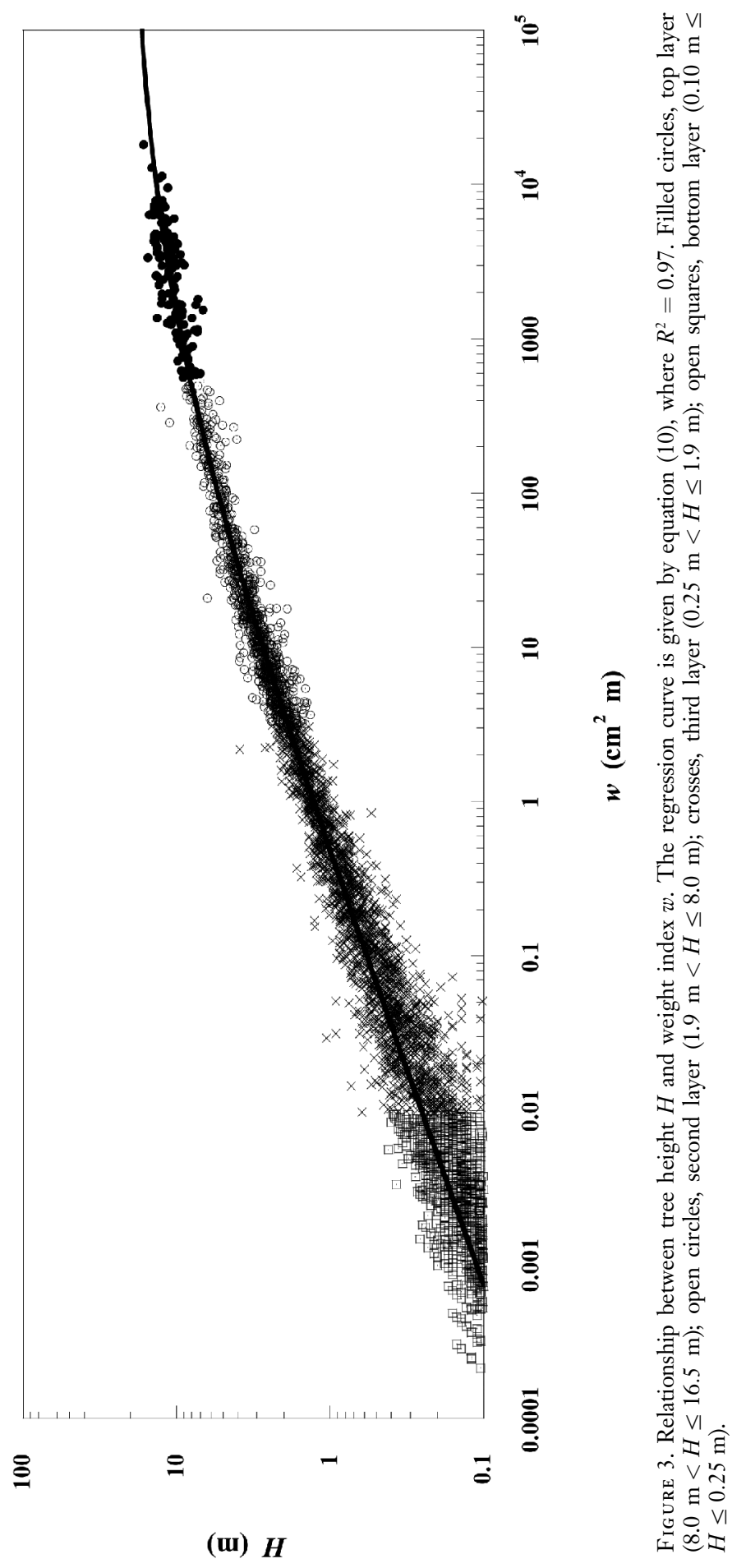


TABLE 1

Diversity Indices for Layer and Tree Size of a Subtropical Evergreen Broadleaf Forest

\begin{tabular}{llcccr}
\hline \hline Layer/Tree Size & Height Range $(\mathrm{m})$ & No. of Trees & No. of Species & $H^{\prime}$ (bit) & $\mathcal{J}^{\prime}$ \\
\hline Top & $8.04<H \leq 16.52$ & 139 & 18 & 2.75 & 0.66 \\
Second & $1.89<H \leq 8.04$ & 953 & 42 & 4.37 & 0.81 \\
Third & $0.25<H \leq 1.89$ & 2,226 & 56 & 4.73 & 0.80 \\
Bottom & $0.10 \leq H \leq 0.25$ & 1,366 & 51 & 4.33 & 0.73 \\
All trees & $0.10 \leq H \leq 16.52$ & 4,684 & 60 & 4.83 & 0.82 \\
Large trees & DBH $\geq 4.5 \mathrm{~cm}$ & 231 & 32 & 3.80 & 0.77 \\
\hline
\end{tabular}

china var. biflora (Sieb.) Mak., Antidesma japonicum Sieb. et Zucc., and Syzygium buxifolium Hook. \& Arn., never appeared in the top layer, indicating that they are shade-tolerant species.

\section{Spatial Distributions of Trees}

The spatial distribution patterns of trees for each layer are shown in Figure 4 based on the unit-size $m_{u}^{*}-m_{u}$ relationship and the $\rho$-index against quadrat size $u$. The spatial distribution of the basic component for all layers except the top layer was found to be a single individual, and the distribution of the basic component was completely random, because the $m_{u}^{*}-m_{u}$ relation line almost mimicked the Poisson line. In the top layer, however, the spatial distribution of trees showed a special trend (i.e., there seemed to exist a triple-clump structure). The $\rho$-index showed three peaks at quadrat sizes 1,4 , and 30 , and clumps of small, intermediate, and large scales tended to be distributed irregularly. The clump sizes were estimated as 6.25 $\mathrm{m}^{2}, 12.5-25 \mathrm{~m}^{2}$, and $100-187.5 \mathrm{~m}^{2}$. The small clump size was a little larger than mean area occupied by individuals of the top layer $\left(5.4 \mathrm{~m}^{2}\right)$.

\section{Overlapping in Spatial Distributions of Trees among the Layers}

The degree of overlapping $\omega$ with successive changes of quadrat size in spatial distributions of trees among the layers combined from the top layer downward is shown in Figure 5. The spatial distributions of trees were over-

TABLE 2

Ten Dominant Species in Order of Species Rank Determined by Importance Value $(I V)$ in the Total Stand

\begin{tabular}{|c|c|c|c|c|c|c|c|}
\hline \multirow[b]{2}{*}{$\begin{array}{l}\text { Species } \\
\text { Rank }\end{array}$} & \multirow[b]{2}{*}{ Species } & \multirow[b]{2}{*}{ Family } & \multicolumn{5}{|c|}{$I V \%$} \\
\hline & & & $\begin{array}{l}\text { Top } \\
\text { Layer }\end{array}$ & $\begin{array}{l}\text { 2nd } \\
\text { Layer }\end{array}$ & $\begin{array}{c}\text { 3rd } \\
\text { Layer }\end{array}$ & $\begin{array}{l}\text { Bottom } \\
\text { Layer }\end{array}$ & $\begin{array}{l}\text { Total } \\
\text { Stand }\end{array}$ \\
\hline 1 & Castanopsis sieboldii (Mak.) Hatusima & Fagaceae & 44.16 & 12.83 & 25.92 & 20.54 & 21.30 \\
\hline 2 & Schima wallichii (DC.) Korth. & Theaceae & 22.82 & 1.69 & 0.62 & 1.69 & 9.30 \\
\hline 3 & Elaeocarpus japonicus Sieb. \& Zucc. & Elaeocarpaceae & 11.03 & 7.46 & 1.73 & 2.78 & 4.61 \\
\hline 4 & Myrsine seguinii Lév. & Myrsinaceae & 0.0 & 4.14 & 5.46 & 7.01 & 3.92 \\
\hline 5 & Ardisia quinquegona $\mathrm{Bl}$ & Myrsinaceae & 0.0 & 4.97 & 6.88 & 3.72 & 3.74 \\
\hline 6 & Smilax china var. biflora (Sieb.) Mak. & Liliaceae & 0.0 & 0.0 & 4.07 & 8.11 & 3.64 \\
\hline 7 & Antidesma japonicum Sieb. \& Zucc. & Euphorbiaceae & 0.0 & 6.96 & 6.23 & 0.91 & 3.59 \\
\hline 8 & Cinnamomum doederleinii Engl. & Lauraceae & 5.87 & 0.41 & 2.0 & 6.20 & 3.27 \\
\hline 9 & Daphniphyllum teijsmannii Zoll. ex Kurz & Daphniphyllaceae & 2.43 & 5.32 & 1.11 & 5.11 & 3.21 \\
\hline 10 & Syzygium buxifolium Hook. \& Arn. & Myrtaceae & 0.0 & 8.59 & 2.47 & 0.62 & 3.04 \\
\hline
\end{tabular}



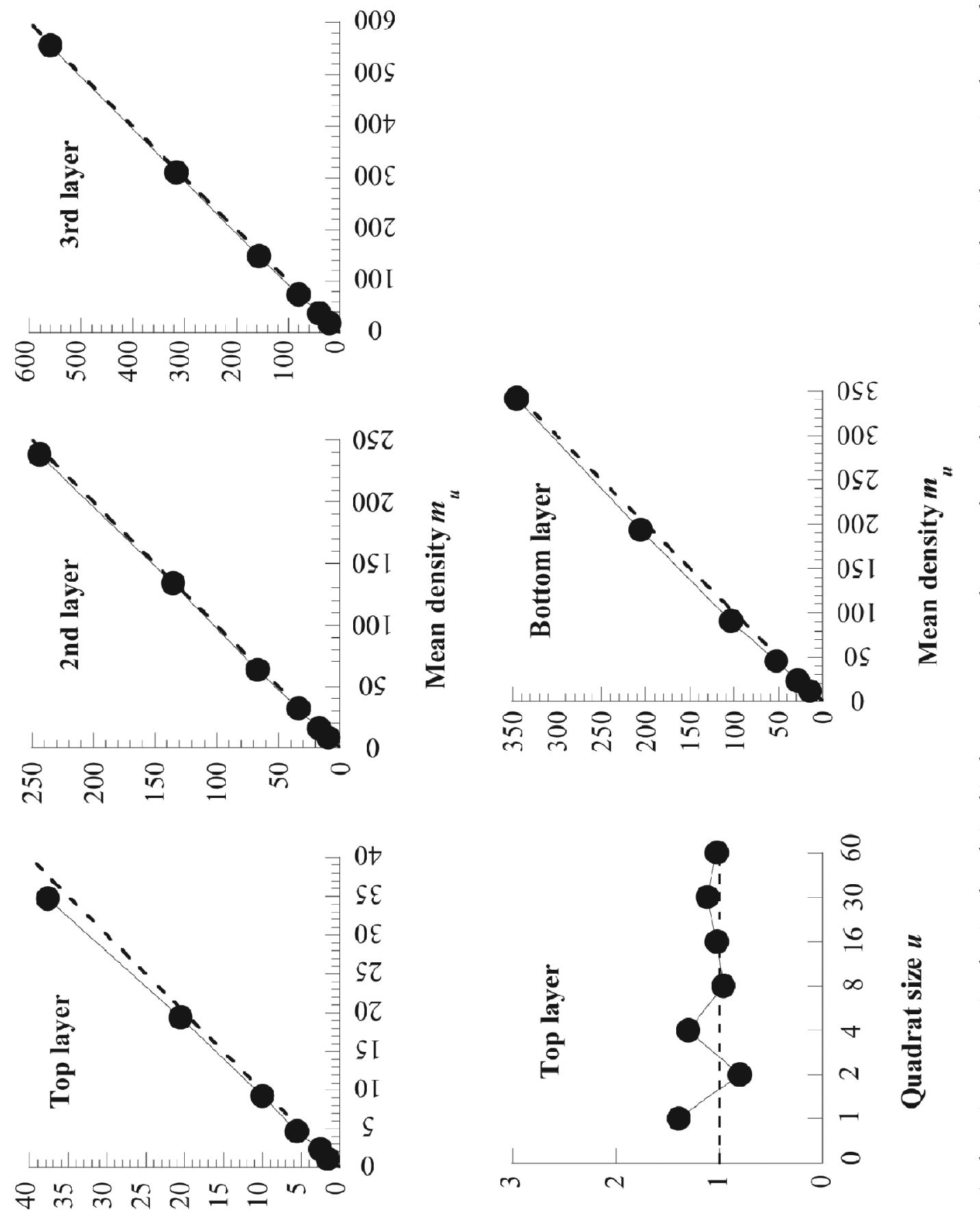

*

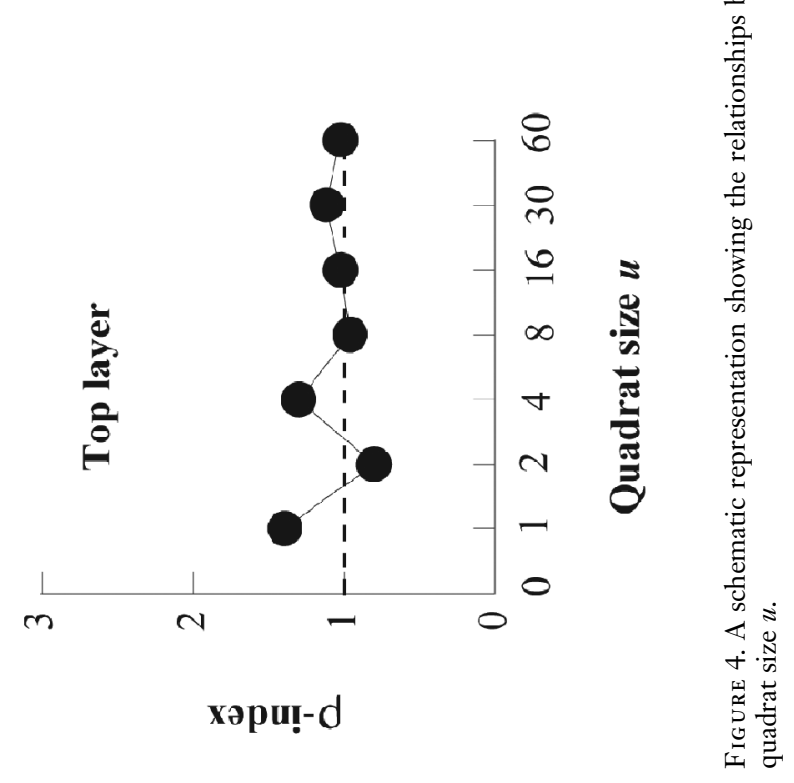




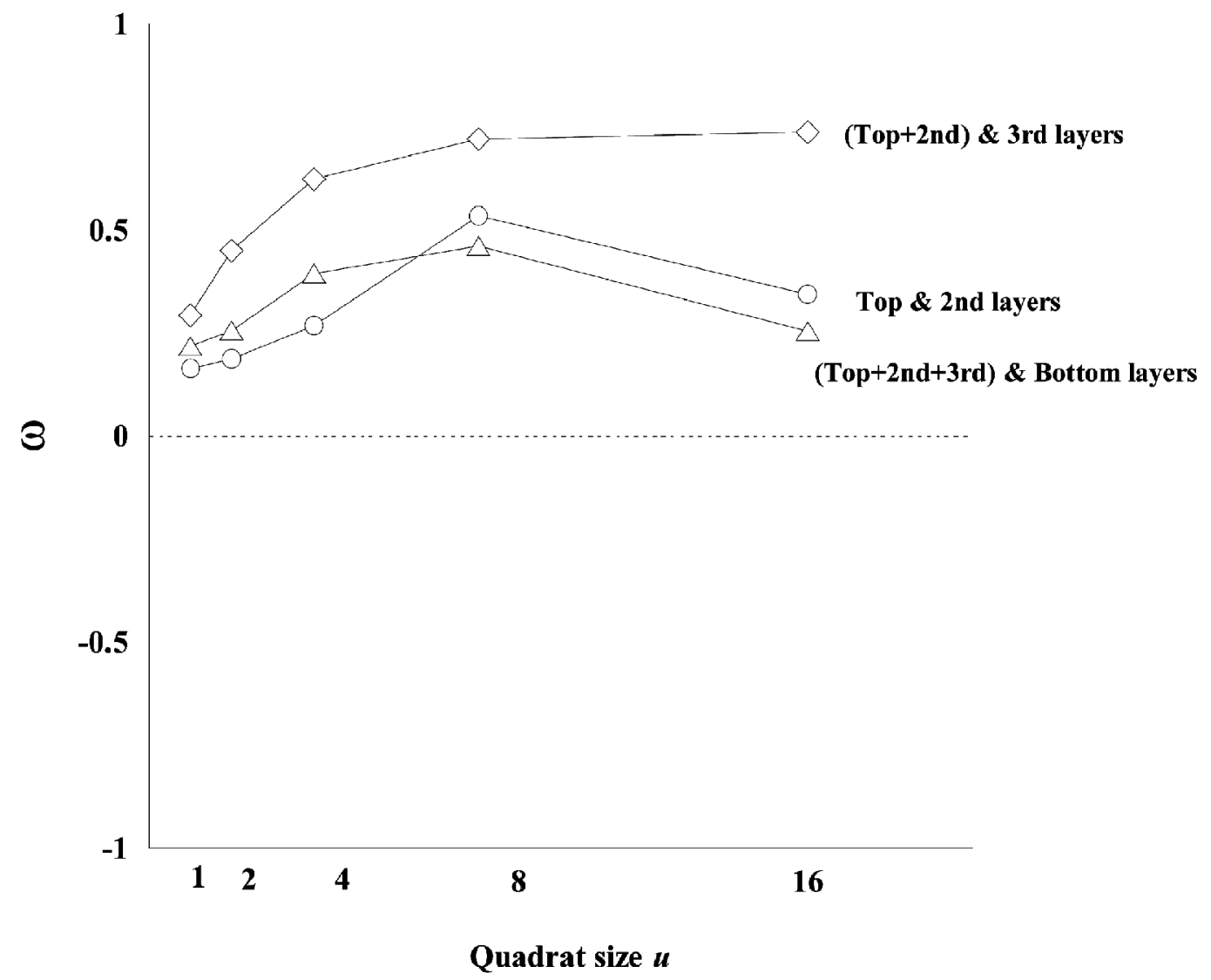

FIgURE 5. Degree of overlapping $\omega$ in spatial distributions of trees among the layers with successive changes of quadrat sizes $u$.

lapped between the top and the second layers, between the top and second layers and the third layer, and also between the top, second and third layers and the bottom layer. These results may indicate that light cannot penetrate easily into the lower three layers. As a result, species in the lower layers must be shade-tolerant.

Mean Weight Index and Density among the Layers

As shown in Figure 6, mean weight index $\overline{w_{i}}$ of the $i$ th layer decreased from the top $(i=1)$ toward the bottom layer $(i=4)$, whereas the opposite trend was observed for the tree density $\rho_{i}$ of the $i$ th layer. This trend was well expressed in the form (Feroz et al. $2006 a, b)$ :

$$
\overline{w_{i}}=K \rho_{i}^{-\alpha}\left(1-\frac{\rho_{i}}{\rho_{\mathrm{o}}}\right)
$$

where the values of coefficients $K, \alpha$, and $\rho_{\text {o }}$ were estimated as $2.23 \times 10^{8} \mathrm{~cm}^{2} \mathrm{~m} \mathrm{ha}^{-\alpha}$, 1.49 , and $24,575 \mathrm{ha}^{-1}$, respectively. The $\alpha-$ value was close to $3 / 2$.

\section{DISCUSSION}

Because the lower layers contained many species relative to their smaller height ranges 


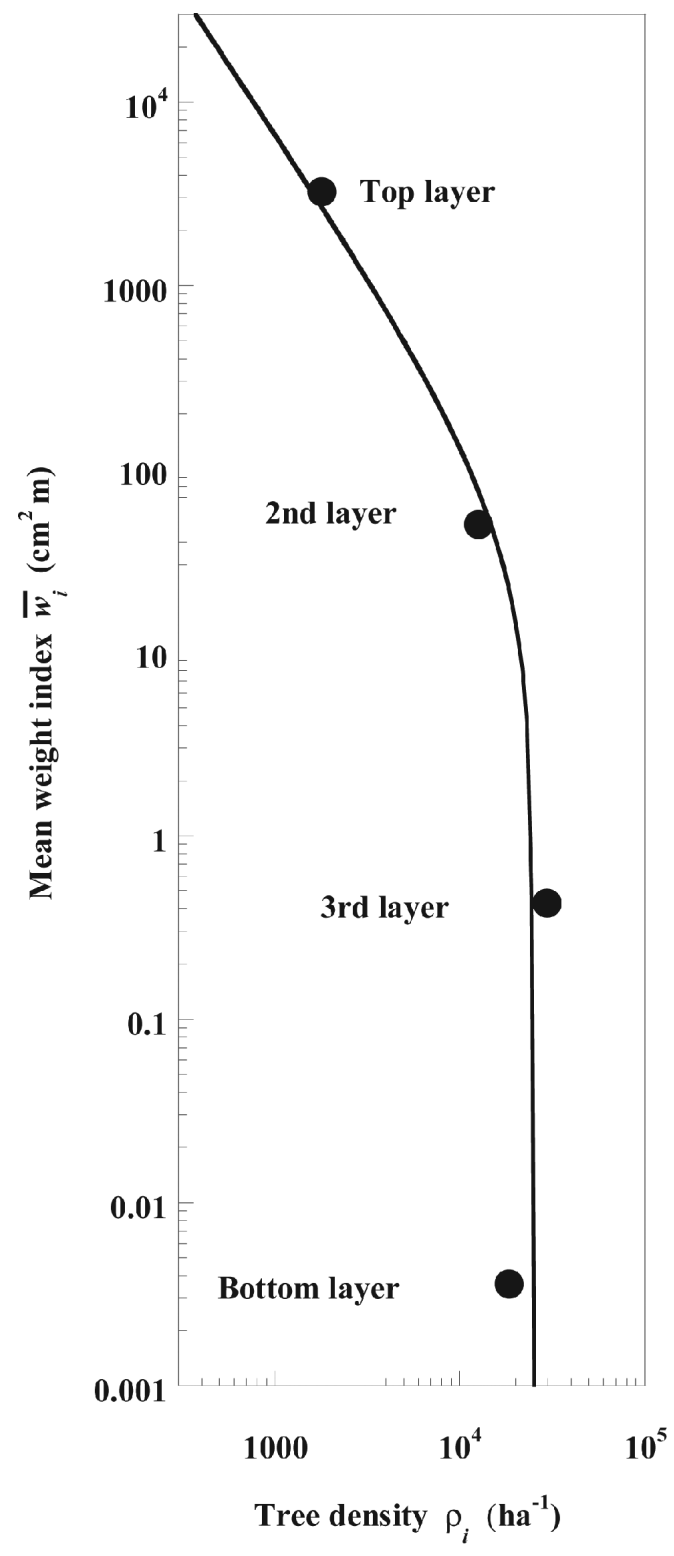

FigUre 6. Relationship between mean weight index $\overline{w_{i}}$ and tree density $\rho_{i}$ among the layers. The curve is given by equation (11), where $R^{2}=0.98$.

(Table 1), obviously those layers support the high species richness of the forest. For example, $85 \%$ of the total species with $30 \%$ of the total individuals were packed within a thin bottom layer $15 \mathrm{~cm}$ in height. The values of $H^{\prime}$ and $\mathcal{F}^{\prime}$ and the number of species of trees having $H \geq 0.10 \mathrm{~m}$ were quite high compared with those of $H^{\prime}$ and $f^{\prime}$ and the number of species of large trees having $\mathrm{DBH} \geq 4.5 \mathrm{~cm}$. This is also mainly caused by a large number of species among small trees, though higher $f^{\prime}$-value has a small influence on the high value of $H^{\prime}$ for trees with $H \geq 0.10 \mathrm{~m}$. Therefore, small trees in the lower layers, especially in the bottom layer, play an important role in maintaining the high woody species diversity of the current forest. The increasing trend of $H^{\prime}$ with successively decreasing height of layers from the top toward the bottom layer in the current forest was different from that in a nearby forest on a limestone substrate, where $H^{\prime}$ decreased with decreasing height of layers (Feroz et al. 2006b), as shown in Figure 7.

Nevertheless, clear-cutting and complete removal of undergrowth of forests in the northern part of Okinawa Island have been proceeding (Azuma et al. 1997, Itô 1997, Itô and Aoki 1999, Itô et al. 2000). These operations not only decrease the woody species diversity of the forest but also affect populations of ground animals, because small trees in the lower layers provide a natural habitat for animals living on the forest floor. In this respect, conservation of small trees in the lower layers, especially the bottom layer, is indispensable to maintain Okinawan evergreen broadleaf forests.

The facultative shade species (lighttolerant under high light conditions and shade-tolerant under low light conditions) can grow from the bottom to the top layer. Castanopsis sieboldii was typically a facultative shade species as well as a climax species because it appeared in all layers with the highest importance value (Table 2). Elaeocarpus japonicus Sieb. \& Zucc., Cinnamomum doederleinii Engl., and Daphniphyllum teijsmannii Zoll. ex Kurz were also facultative shade species. Schima wallichii was typically a sun species (or pioneer species) because it appeared in the top layer with a tremendously high importance value, but it had a very low importance value in the lower three layers. On the 


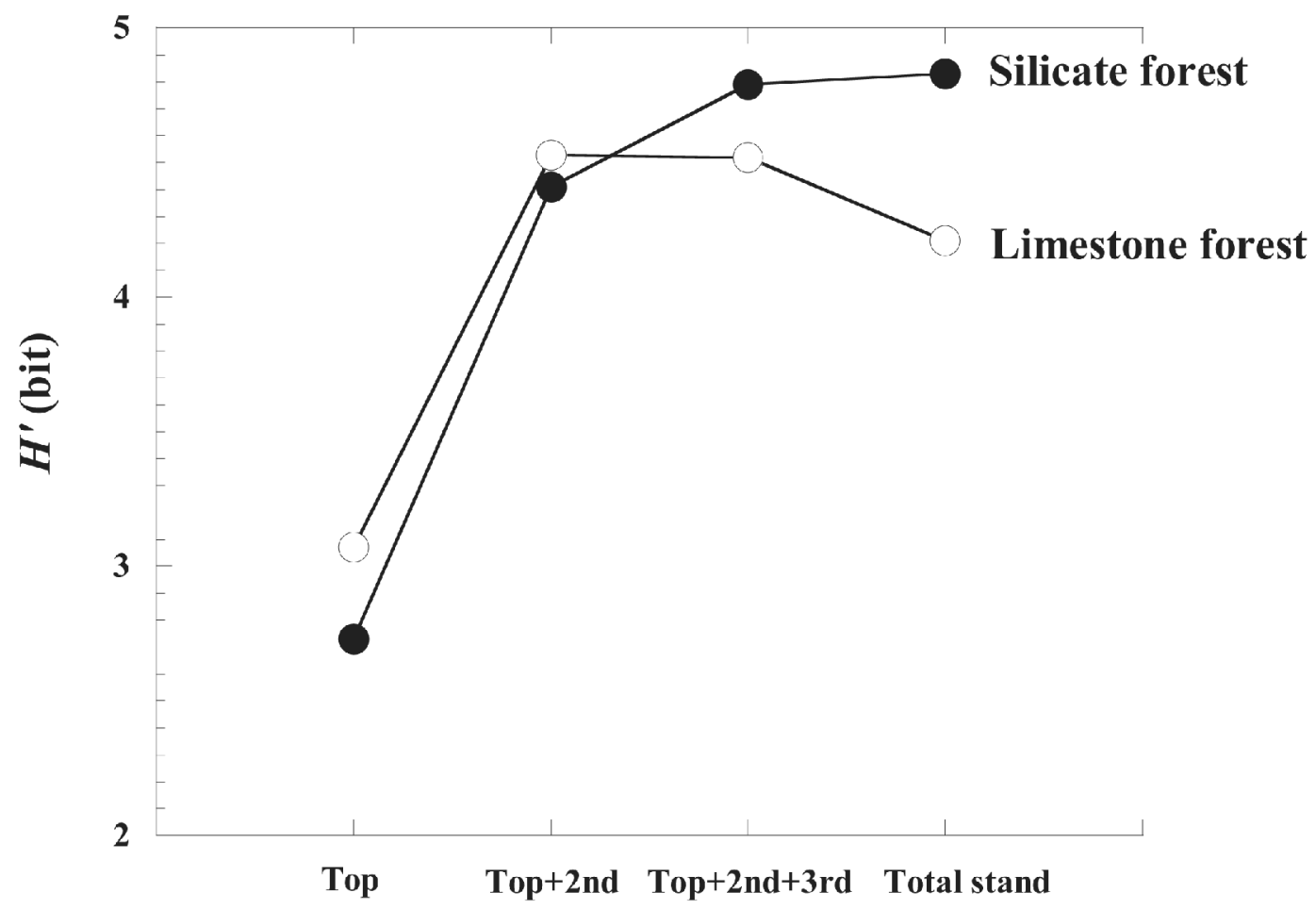

\section{Layer}

FIgURE 7. Trends of $H^{\prime}$ along the layers combined from the top downward in the current forest and the forest grown on a limestone substrate (Feroz et al. 2006b).

other hand, Smilax china var. biflora (Sieb.) Mak. was typically a shade species because it had a high importance value in the lower two layers, and it never appeared in the upper two layers.

The relationship of mean weight index to tree density in each layer is analogous to the mean plant weight-density trajectory of selfthinning even-aged plant populations (Hagihara 2000), which start growing from initial plant densities lower than the initial plant density of the population obeying the $-3 / 2$ power law of self-thinning (Yoda et al. 1963). The relationship described by equation (11) may be more general for subtropical forests than the quasi-1/2 power law of tree height proposed by Yamakura (1988), because all trees were considered in the present forest, whereas the quasi-1/2 power law was established only for large trees.

\section{ACKNOWLEDGMENTS}

We are grateful to our colleagues, L. Alhamd, M. N. I. Khan, R. Suwa, K. Nakamura, B. Tanaka, and P. Wane, for their cooperation and active participation in the fieldwork. We thank Mrs. J. Ferdousi for her assistance and active participation in the field. Thanks go to T. Shinzato and T. Enoki, Subtropical Field Science Center at Yona, University of the Ryukyus, for permitting us to access their facilities. 


\section{Literature Cited}

Alhamd, L., S. Arakaki, and A. Hagihara. 2004. Decomposition of leaf litter of four tree species in a subtropical evergreen broad-leaved forest, Okinawa Island, Japan. For. Ecol. Manage. 202:1-11.

Alhamd, L., and A. Hagihara. 2004. Litterfall of a subtropical evergreen broad-leaved forest in Okinawa Island, Japan. Tropics 13:255-268.

Azuma, S., T. Sasaki, and Y. Itô. 1997. Effects of undergrowth removal on the species diversity of insects in natural forests of Okinawa Hontô, Pacific. Conserv. Biol. 3:156-160.

Bunyavejchewin, S., J. V. LaFrankie, P. J. Baker, M. Kanzaki, P. S. Ashton, and T. Yamakura. 2003. Spatial distribution patterns of the dominant canopy dipterocarp species in a seasonal dry evergreen forest in western Thailand. For. Ecol. Manage. 175:87-101.

Feroz, S. M., A. Hagihara, and M. Yokota. 2006a. Stand structure and woody species diversity in relation to the stand stratification in a subtropical evergreen broadleaf forest, Okinawa Island. J. Plant Res. 119:293-301.

Feroz, S. M., K. Yoshimura, and A. Hagihara. 2006b. Architectural stratification and woody species diversity of a subtropical broadleaf forest grown in a limestone habitat in Okinawa Island, Japan. Enformatika $17: 237-242$.

Goldman, S. 2005. Information theory. Dover, New York.

Hagihara, A. 2000. Time-trajectory of mean phytomass and density in self-thinning plant populations. Bull. Fac. Sci., Univ. Ryukyus 70:99-112.

Hatusima, S. 1990. Flora of the Ryukyus. Okinawa Biological Education, Naha.

Hozumi, K. 1971. Studies on the frequency distribution of the weight of individual trees in a forest stand. III. A beta-type distribution. Jpn. J. Ecol. 21:152-167.

. 1975. Studies on the frequency distribution of the weight of individual trees in a forest stand. $\mathrm{V}$. The $M-w$ diagram for various types of forest stands. Jpn. J. Ecol. 25:123-131.

Itô, Y. 1997. Diversity of forest tree species in Yanbaru, the northern part of Okinawa Island. Plant. Ecol. 133:125-133.

Itô, Y., and J. Aoki. 1999. Species diversity of soil-inhabiting oribatid mites in Yanbaru, the northern part of Okinawa Hontô, and the effects of undergrowth removal on it. Pedobiologia 43:110-119.

Itô, Y., K. Miyagi, and H. Ota. 2000. Imminent extinction crisis among the endemic species of the forests of Yanbaru, Okinawa, Japan. Oryx 34:305-316.

Iwao, S. 1972. Application of the $m^{*}-m$ method to the analysis of spatial patterns by changing the quadrat size. Res. Popul. Ecol. 14:97-128.

- 1977. Analysis of spatial association between two species based on the interspecies mean crowding. Res. Popul. Ecol. 18:243-260.

Kimmins, J. P. 2004. Forest ecology. Pearson Education, Inc., New Jersey.

Kira, T. 1977. Forest vegetation of Japan. Introduction. Pages 1-9/14 in T. Shidei and T. Kira, eds. Primary productivity of Japanese forests: Productivity of terrestrial communities. University of Tokyo Press, Tokyo.

. 1991. Forest ecosystems of East and Southeast Asia in a global perspective. Ecol. Res. 6:185-200.

Kira, T., and H. Ogawa. 1971. Assessment of primary production in tropical and equatorial forests. Pages 309-321 in Productivity of forest ecosystems. UNESCO, Paris.

Lloyd, M. 1967. Mean crowding. J. Anim. Ecol. 36:1-30.

MacArthur, R. H., and J. W. MacArthur. 1961. On bird species diversity. Ecology 42:594-598.

Magurran, A. E. 1988. Ecological diversity and its measurement. Princeton University Press, Princeton, New Jersey.

Ohsawa, M. 1995. Latitudinal comparison of altitudinal changes in forest structure, leaftype, and species richness in humid monsoon Asia. Vegetatio 121:3-10. 
Pielou, E. C. 1969. An introduction to mathematical ecology. John Wiley \& Sons, New York.

\section{New York.}

Roberts, M. R., and F. S. Gilliam. 1995. Patterns and mechanisms of plant diversity in forested ecosystems: Implications for forest management. Ecol. Appl. 5:969977.

Yamakura, T. 1987. An empirical approach to the analysis of forest stratification. I. Proposed graphical method derived by using an empirical distribution function. Bot. Mag. Tokyo 100:109-128.

1988. An empirical approach to the analysis of forest stratification. II. Quasi$1 / 2$ power law of tree height in stratified forest communities. Bot. Mag. Tokyo 101:153-162.

Yoda, K., T. Kira, H. Ogawa, and K. Hozumi. 1963. Self-thinning in overcrowded pure stands under cultivated and natural conditions (Intraspecific competition among higher plants XI). J. Biol. Osaka City Univ. 14:107-129. 